Stormer ${ }^{1}$ has stated that the lower limit of height observed in Norway is $80 \mathrm{~km}$. In connexion with this, our observations of April 16 and April 20, 1933, are particularly interesting. On these two occasions bands were photographed the lower limits of which were at a height of only $60 \mathrm{~km}$. Thirty-seven measurements were made on auroral features the heights of which were less than $80 \mathrm{~km}$., and eighteen of these showed heights of less than $70 \mathrm{~km}$., the lowest recorded being $59 \mathrm{~km}$. In these photographs the intensity was good and the edge of the aurora clearly defined. The calculations were made by the 'network chart' method of Harang and Tonsberg ${ }^{2}$, and the direction of the displacement of the aurora relative to the fixed stars was quite favourable. The length of the base line used for the photographs was $112 \mathrm{~km}$.

In addition to the results described above, several measurements were made on long ray structures in the aurora. One of these was found to extend from a height of $336 \mathrm{~km}$. at its upper limit to a height of $71 \mathrm{~km}$. at its base, while a second extended from $155 \mathrm{~km}$. to $74 \mathrm{~km}$. It therefore appears that, in Western Canada, the lower limit of the auroral displays is nearer to the earth's surface than in Norway.

These results will be published in detail later as part of the Canadian contribution to the International Polar Year work.

T. Alty. F. J. Wirson.

University of Saskatchewan,

Saskatoon, Saskatchewan. March 10.

1 Stermer, "Photographic Atlas of Auroral Forms", Supplement 1, p. 8.

Harang and Tonsberg, "Investigations of the Aurora Borealis at Nordlys Observatoriet, Tromso", Geofys. Pub., 9, No. $5 ; 1932$.

\section{Meteorology of a Gliding Flight}

As meteorologists have shown a certain amount of interest in the experience of glider pilots, the following brief account of my flight from Dunstable to Rayleigh, in Essex, on April 22 may be worth recording.

The flight was made in a high performance sailplane, the Rhönadler 32, hand-launched from Dunstable Downs, which at this point rise some $200 \mathrm{ft}$. above the surrounding country and about $850 \mathrm{ft}$. above sea-level. The wind direction was approximately due west and velocity about 8 m.p.h. At 10.30 a.m. cumulus clouds formed rapidly, and on taking off at noon the sky was three-quarters covered with this type. The instruments carried were a barograph, an altimeter, air speed indicator, variometer and compass.

After slope soaring for a few minutes at a height of only $100 \mathrm{ft}$., I detected the rising current under a small cumulus and promptly circled in the manner of the convection soaring birds. The machine rose steadily some $2,000 \mathrm{ft}$., when I decided to fly upwind under a much larger cloud which appeared to be in the process of formation. This decision proved very beneficial, as only a few hundred feet were lost in the journey, and height was very rapidly regained under the cloud. At 3,500 ft. I entered the cloud base and thus commenced my first cloud flight with neither parachute nor appropriate instruments-a distinctly stirring experience. The rising current inside the cloud was considerably more violent than underneath it, so much so that one felt definitely forced into the seat. Unfortunately, my variometer, an experimental type, was not working very well so I cannot say what was the maximum rate of climb. I emerged from the side of the cloud at approximately $5,000 \mathrm{ft}$. above the start in brilliant sunshine and steered in a south-easterly direction, finally landing near Southend; an approximate distance of 54 miles from the start.

The flight could undoubtedly have been prolonged but for the fact that London's smoke caused a thick haze, and the cloud form degenerated into a stratiform type with only a weak rising current.

The lowest altitude recorded was 1,200 ft., but circling under and into a cloud again restored me to $5,000 \mathrm{ft}$.

Perhaps meteorologists could tell us if a sensitive thermometer would be useful in detecting rising air and also indicate, generally, how sailplane pilots can assist the science of meteorology.

$$
\begin{gathered}
\text { London Gliding Club, } \\
\text { Dunstable, } \\
\text { Beds. }
\end{gathered}
$$

\section{Field Studies and Physiology: a Further Correlation}

IN a previous letter to NATURE ${ }^{1}$ one of us directed attention to certain striking correlations between the findings independently arrived at by physiologists in the laboratory and students of bird behaviour in the field. Since then a further parallelism has come to light which it seems of sufficient interest to record. Wiesner and Sheard ${ }^{2}$ state that partial removal of the prepituitary in adult male rats usually results in what they style 'partial diserotisation'. The normal copulatory process consists in a definite and rapid sequence of acts. In partially hypophysectomised males, the sequence is usually slowed down and interrupted, consisting merely of hesitant acts of mounting, often abortively repeated many times.

Observations on moorhens (Gallinula chloropus) show that behaviour of a similar nature is often encountered in the wild state. Here too the normal male mating process consists of a sequence of actions, usually performed very rapidly so as to appear like a unitary act. During cold disagreeable weather, however, the sequence is often much slowed down, and interrupted in the middle. For example, after mounting on the female's back, the male may appear confused, and after an interval of hesitation descend without proceeding further. Or the sequence may be interrupted earlier, for example, after the male has merely placed a foot on the female's back. A curious fact is that such incomplete sex behaviour usually ends in the male viciously pecking the female.

Such behaviour is to be observed in the same birds which on previous fine days had been mating normally. The cold appears to act more or less quantitatively, very cold weather entirely extinguishing all sexual behaviour, moderate cold inducing only slight 'diserotisation'. Poultry-keepers are familiar with similar effects of cold weather on cocks.

Pavlov $^{3}$ has observed similar phenomena in nonsexual reactions in his experimental dogs, both as regards the dissociation of acts normally associated, and in the slowing down and the meaningless repetition of acts. In addition, 'negativism', a negative reaction to a stimulus which usually induces a positive reaction, is often seen : this may be compared with the male moorhen's incomplete 